\title{
Blok Zinciri (Blockchain) Teknolojisi ve İşletme Uygulamaları: Genel Bir Değerlendirme
}

Hüseyin AVUNDUK ${ }^{1}$

\author{
Hakan AŞAN ${ }^{2}$
}

\begin{abstract}
$\ddot{O} z$
Günümüzde teknolojinin gelişmesi ve yaygınlaşması birçok yapısal değişikliği de beraberinde getirmiştir. Internet ă̆ının ve yazılım mimarisinin gelişiminin öncülüğ̈̈nde eşten-eşe iletişim mantığ ile merkezi olmayan bir çevre oluşturulabilmektedir. Bu anlamda belirli bir merkez olmadan eşler arasında iletişim sağlayan kriptografik veriler ve dă̆ıtık bir sistem yapısına sahip yeni bir teknolojiden bahsedebiliriz. Aslında benzer uygulamalar geçmiş dönemlerde ortaya çıkmış olsa da blok zinciri bu yapıyı farklı noktalara taşımıştır. Özellikle kripto paraların yaygınlaşması finans sistemlerinin bakış açısını değiştirmiştir. Bu çalışmada blok zincirinin temel çalışma mantığ anlatılmıştır. Blok zincirinin örnek uygulamaları ortaya koyulmuş ve blok zincirinin çeşitli açılardan eksik yönleri ve gelecekte oluşabilecek olası sorunlara değinilmiştir.
\end{abstract}

Anahtar Kelimeler: Blok Zinciri, Kripto Para, İsletme Uygulamaları.

Jel Sinıflandırma Kodları: M110, M150.

\section{Block Chain Technology and Business Practices: A General Owerview}

\begin{abstract}
Today, the development and widespread use of technology has brought about many structural changes. In the pioneer of the development of the Internet network and the software architecture, a decentralized environment can be created with the principle of peer to peer communication. In this sense, we can talk about a new technology that has a distributed system structure and cryptographic data that provides communication between peers without a specific center. In fact, similar implementations have emerged in the past, but blockchain technology has done it differently.In particular, the widespread use of cryptographic money has changed the perspective of financial systems. In this study, the basic working logic of the block chain is explained.The application examples of the block chain are presented and the missing aspects of the block chain from various angles and possible future problems are addressed.
\end{abstract}

Keywords: Block Chain, Crypto Money, Business Practices.

Jel Classification Codes: M110, M150.

${ }^{1}$ Dr. Öğr. Üyesi, Dokuz Eylül Üniversitesi, İktisadi ve İdari Bilimler Fakültesi, İşletme Bölümü, huseyin.avunduk@deu.edu.tr

2 Araş. Gör., Dokuz Eylül Üniversitesi, İzmir Meslek Yüksekokulu, İktisadi ve İdari Programlar, hakan.asan@deu.edu.tr 


\section{GíRiş}

\section{H.AVUNDUK - H.AŞAN}

2009'da Bitcoin (sanal) para biriminin piyasaya sunulmasından bu yana, blok zincir teknolojisi büyük bir ilgi konusu olmuştur. İlk başlarda birçok kişi bu yeni sanal para birimine karşı şüphe ile yaklaşmıştır. Bununla birlikte, Bitcoin para biriminin değeri 2013 y1lında 13.96 USD / BTC (7 Ocak 2013) seviyesinden 979.45 USD / BTC (Kasim 25, 2013) seviyesine kadar yükselmiştir. Bu yıl içinde Bitcoin’ e yatırım yapanlar kabaca \%7000 civarında gelir elde etmişlerdir. O tarihten bu yana, fiyat endeksi oldukça dalgalı bir seyir izlemiştir ve bugün itibari ile 14.600 USD / BTC seviyesinde (07.12.2017) işlem görmektedir ve bu yükselişin durmasına dönük bir belirti bulunmamaktadır. Bitcoin, bu durumun yanında hukuki çerçevelerin ötesinde işlev gören yeni marketler ve finansal araçları ortaya çıkarmıştır. Bu, herhangi bir merkezi regülatörden bağımsız olarak para birimi oluşturulmasını sağlayan blok zinciri teknolojisinin merkezi olmayan biçimi sayesinde mümkün olmuştur (Vardi, 2016). Bu anlamda sorgulanması gerek durum, bu para birimini o kadar özel kılan nedir ve onun arkasındaki teknolojiyi nasıl kullanılabilir olmalıdır. $\mathrm{Bu}$ sorunun yanıt1, Blok Zinciri (Blockchain) adı verilen teknolojidir. Bitcoin uygulaması ile kendi kanıtlayan Blockchain teknolojisini kullanarak yeni uygulama alanlarını keşfetmek için şirketler ve kurumlar oldukça istekli hale gelmişlerdir. Başta finans şirketleri olmak üzere, perakende sektörü, kamu kuruluşları, sigorta şirketleri gibi birçok alanda faaliyet gösteren önde gelen kuruluşlar büyük bir ilgi göstermektirler ve bu konu üzerine uygulama geliştirme çabaları içine girmektedirler. Bu çalışmada, son zamanlarda tüm dünyada yakın ilgi gören Blok Zincir Teknolojisinin tanımı, çalışma mekanizması, özellikleri ve uygulama alanları gibi konuları ele almak ve Türk akademik yazınında fazlaca işlenmemiş bu konuya yönelik 
Dokuz Eylül Üniversitesi İktisadi ve İdari Bilimler Fakültesi Dergisi Cilt:33, Sayl:1, Yll:2018, ss. 369-384

yapılabilecek akademik çalışma önerilerinin ortaya konulması amaçlanmıştır.

\section{BLOK ZİNCİRİ TEKNOLOJISİ}

Blok zinciri (Blockchain) kelimesi, Satoshi Nakamoto’ nun 2008 yılında yayınlanan orijinal Bitcoin başlıklı makalesinde dile getirilmiştir. Blockchain kelime olarak bu makalede geçmemiş olsa da, kripto paranın altında yatan bir teknoloji bileșenini, kriptografik olarak birbirine zincirlenmiş bir dizi veri bloğu olarak tanımlanmaktadır (Satoshi, 2008). Bitcoin, blok zincir teknolojisinin ilk uygulamasıdır (Iansiti ve Lakhani, 2008). Yaygınlaşmasının en büyük adımlarından birisidir. Bu yayılıma karşı hukuk bilimcilerinden ve yasa koyuculardan gelen ilk tepki, Bitcoin'in nasıl düzenlenmesi gerektiği üzerinedir. (De Filippi, 2014; Shcherbak, 2014; Tu ve Meredith 2015). Ancak blok zincir teknolojisi sadece Bitcoin olarak değil diğer birçok alanda da uygulanabilir. Blockchain teknolojisinin işleyişini daha iyi anlayabilmek için aşağıda, Nikolai Hampton tarafından yapılan benzetmeden türetilen blockhain teknolojisinin ilk uygulaması olan Bitcoin Blockchain'nin basitleştirilmiş bir açıklaması verilmiştir (Hampton, 2016);

Bitcoin Blockchain, her bir sayfasında bitcoin sanal parası ile yapılan yaklaşık on dakikalık işlemlerin kayıtlarını içeren fiziksel bir defter olarak düşünülebilir. Bir sayfa yeni işlemlerle dolduğunda, zaman damgalı, benzersiz bir seri numarasıyla imzalanmış ve kitaba yapıştırılmıştır. $\mathrm{Bu}$ benzetmede, sayfalar blokları, seri numaralar bloklar arasındaki bağlantıyı temsil eder. Seri numarası, o sayfadaki işlemlerin bir ürünüdür ve bitişik sayfaların seri numaraları, sağlam bir sayfalar zinciri oluşturmak üzere matematiksel bir işlevle birlikte kilitlenir. $\mathrm{Bu}$, sayfaların seri numarasını değiştirmeden işlemlerden birini değiştirmeyi ve dolayısıyla o sayfa ile bir sonraki sayfa arasındaki bağlantıyı imkânsız kılar. Defterdeki bir işlemi 


\section{H.AVUNDUK - H.AŞAN}

değiştirmek için işlemden sonraki tüm sayfaları çıkarmak ve bu sayfaları yeni işlemlerle doldurmak, yeni seri numaralar oluşturmak ve tüm sayfaları deftere yapıştırmak gerekir. Bu defterin kullanıcıları, her zaman, en çok sayfanın bulunduğu kitabı gerçek kitap olarak değerlendirirler. Bu yüzden defter her on dakikada bir yeni sayfa eklenmesi ile büyümeye devam eder ve böylece defterdeki bir işlem geçmişini yeniden başarı ile yazmak isteyen kişinin, topluluğun geri kalanının tamamından daha hızlı çalışması gerekecektir. Yani bu işlemi bir kişinin yapabilmesi için gereken çabanın miktarı, tek bir kişinin yapabileceğinin çok çok üstündedir bu yüzden bu yapı oldukça güvenlidir.

Sonuç olarak, blok zinciri kriptografi teorisine dayalı olarak üretilen bir veri bloğundan oluşur (Nakamoto, 2008). Ayrıca sistem güvenilir bir üçüncü tarafa ihtiyaç duymadan bireyler arasında işlem yapılabilecek bir yapıyı sunmaktadır. Herkes, tüm işlem geçmişini görebilir. İşlem geçmişinin eksiksiz olması da her sanal paranın geçerliliğini sağlar ve tüm sanal paralar oluştukları andan itibaren izlenebilir. Ayrıca teknolojisi sayesinde çözünürlük sağlayarak geriye dönük şeffaflık sağlar. Geçerli kayıtların değiştirilmesini engeller. Bu sistemde yönetime ihtiyaç duymasını ortadan kaldırır. Bu işlem düşük maliyetli işlemler sağlar (Beck vd, 2016)

Blok Zincirinin temel çalışma mantığı Şekil 1. de verilmiştir; 


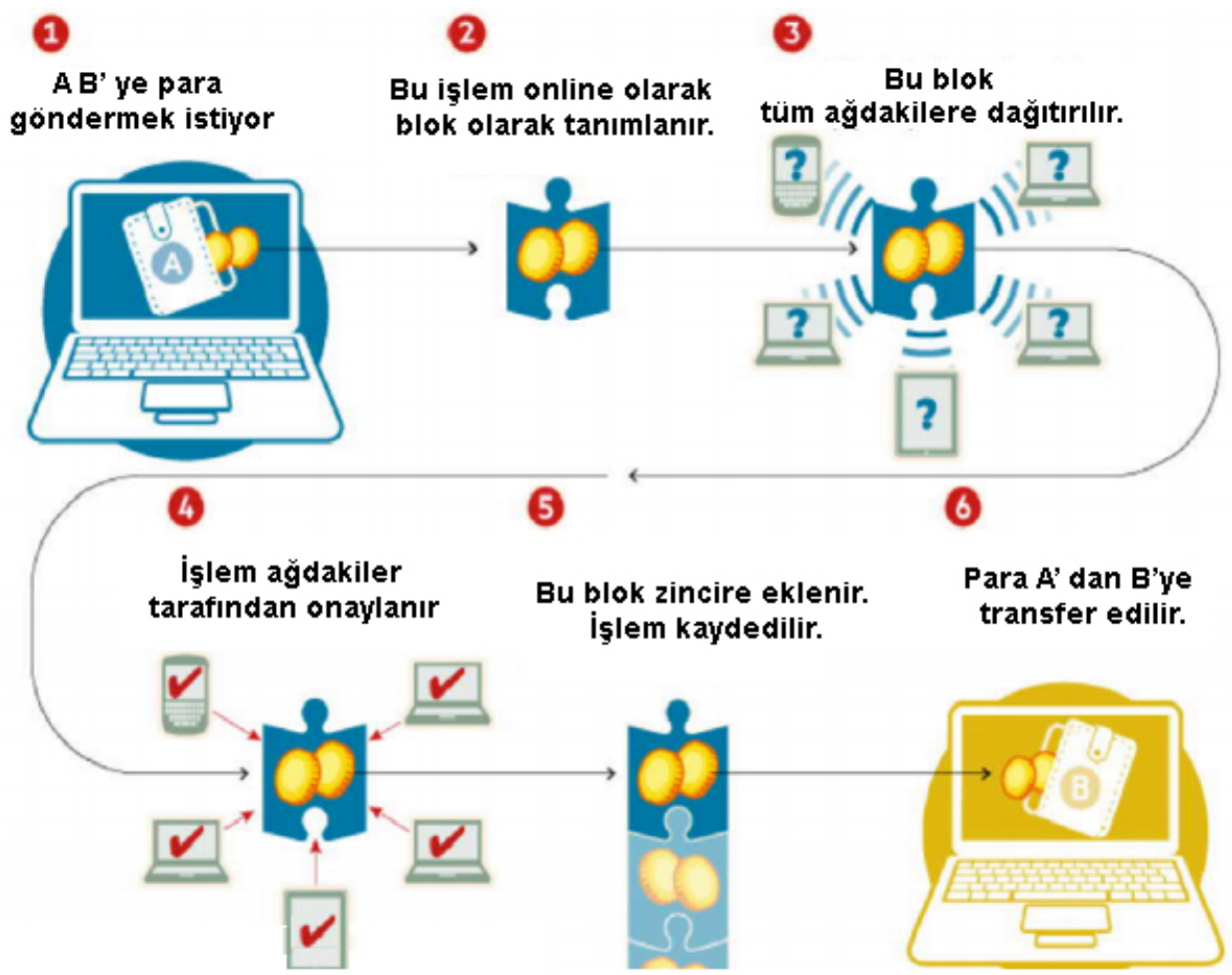

Şekill. Blok Zincir Çalışma Mantığı Kaynak: Crosby,2016.

\subsection{Blok Zinciri Tanım}

Literatürde araştırmacıların üzerinde anlaştı̆̆ı bir tanım ile karşılaşamamaktayız ve yapılan tanımlar ayrıntılarda da olsa farklılıklar göstermektedir. Genel bir tanım olarak Tian; "Blok Zincirinin özünün, merkezi olmayan ve güvenilir yöntemlerle topluca tutulan güvenilir bir veri tabanının teknik bir planı" olduğunu belirtmektedir (Tian, 2016).
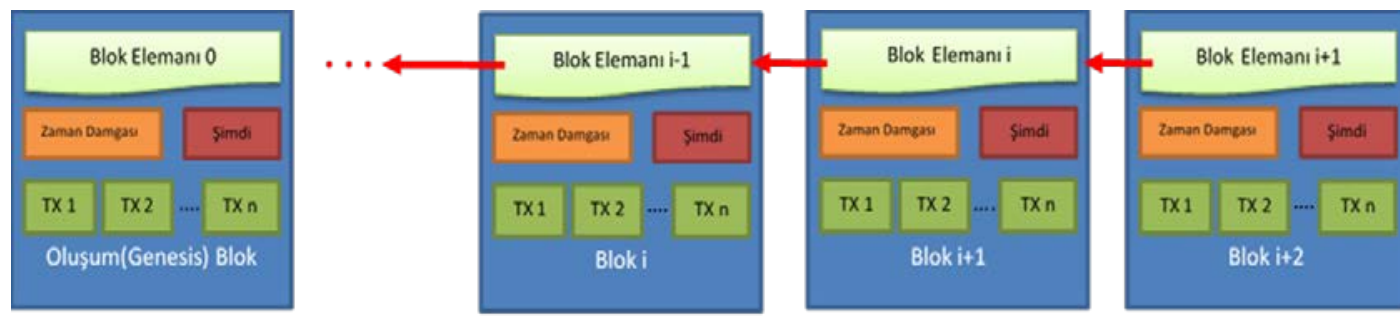

Şekil 2. Blok Zincir Mimarisi Kaynak: Zeng vd., 2016. 


\section{H.AVUNDUK - H.ASSAN}

Blok zincir mimarisi Şekil 2 de verildiği gibidir. Zincir Oluşum (Genesis) bloğu ile başlar. Her blok bir önceki değere içinde bulunduğu değer ile bağlanır. Bir önceki blok onun üst bloğu oluk adlandırılır ve sistem bu şekilde devam ederek sonsuza kadar uzanır.

\subsection{Blok Zinciri Karakteristikleri}

\subsubsection{Dağıtık Veri Tabanı}

Blok zincir teknolojisi dağıtık veritabanı yapısındadır (Iansiti ve Lakhani, 2008) (Lemieux, 2016) (Yli-Huumo vd, 2016) (Xu vd, 2016). Veritaban1 düğümler arasında dağınık bir şekildedir. Bazı araştırmacılar bunların bir bilgisayar olduğunu belirtirken Lemieux ve diğer yazarlar genel bir tanım olarak onları sistemin bir parçası olarak değerlendirir (Iansiti ve Lakhani, 2008).

Block teknolojisi sistemindeki düğümler tüm veritabanına erişilebilir, ancak tek bir dügümün blok zincirinde depolanan verilerin kontrol edemez. Blok zincirindeki her yeni kayıt girdisi (işlemler) hiçbir aracıya ihtiyaç duymadan sistemdeki tüm düğümler tarafından doğrulanır (Iansiti ve Lakhani, 2008) (Yli-Huumo vd, 2016).

\subsubsection{Uçtan Uça İletişim}

Taraflar arasında iletişim kurulması için herhangi bir merkezi yapı kullanılması yerine bireysel dügümler bilgileri eşler arası bir ağda birbirlerine doğrudan iletir ve depolar (Satoshi, 2008) (Iansiti ve Lakhani, 2008) (Yli-Huumo vd, 2016). Blok zinciri sistemdeki düğümler arasında fikir birliği nedeniyle merkeze ihtiyaç duyulmaz (Pilkington, 2016). Blok zincirinde bilgiler BitShares (BTS) içindeki tüm düğümler tarafından saklanır (Iansiti ve Lakhani, 2008). Bazı yazarlar blok zincirinin tüm dügüumler tarafından depolanmadığını ancak tüm düğümler tarafından kullanılabileceğini iddia etmektedirler (Satoshi, 2008) (Yli-Huumo vd, 
2016). Ayrıca yeni işlemlerin tüm bloklara ulaşmak zorunda olmadığını, aksine işlemin zamanla bir bloğa dahil olabilmesi için "yeterli sayıda" düğ̈̈mlere erişmesi gerektiğini belirtmektedirler.

\subsection{3. Șeffaflık}

Blok zinciri teknolojisinde şeffaflık kavramı tüm blokların tüm işlemleri görebilmesi ile gerçekleşir (Iansiti ve Lakhani, 2008) (Yli-Huumo vd, 2016). Bu durum üçüncü bir taraf tarafindan yönetildiği merkezi bir sistemden daha şeffaf olduğunu belirtir.

Birçok kaynak blok zinciri teknolojisinin sahipsiz olduğunu söyler (Tian, 2016) (Yli-Huumo vd, 2016), Nakamoto’ nun raporunda belirttiği gibi. Iansiti and Lakhani (2017) blok zincirini takma isimli olduğunu belirtir. İşlemlerin tamamen kimliği belirsiz kişiler tarafından yapıldığı nakit işlemler aksine, Bitcoin işlemleri her zaman bir hesapla ilişkilendirilir. Her kullanıcı kendi kimliğinin tespit edilmesi için benzersiz bir adrese yani takma ada sahiptir ve işlemler bu takma adlar üzerinden gerçekleşir (Iansiti ve Lakhani, 2008). Blok zinciri teknolojisinde kullanıcılar bu takma adlar sayesinde isimsiz kalacak ve gerçek kimliklerini açıklamaya gerek duymayacaklardır.

\subsubsection{Kayıtların Geri Dönüşsüzlüğü}

Blok zincir teknolojisi depolanan kayıtların geri döndürülememesi adına hesaplama algoritmaları ve yaklaşımları kullanır (Iansiti ve Lakhani, 2008). Buna rağmen Nakamoto (2008) yılında yayınladığı bir raporda dönüşümün imkânsız olmak yerine "dönüşümün hesaplama için pratik olmadığını” iddia etmiştir. "Zincir" terimi zincir üzerindeki kronolojik bir sırada önceki kayıtlarla bağlantılı olan tüm yeni kayıtlardan kaynaklanmaktadır (Iansiti ve Lakhani, 2008). Blok zinciri, şimdiye kadar blok zincir içindeki tüm işlemleri depolar. Zinciri bozmadan eski bir bloğun içindeki bilgiyi 


\section{H.AVUNDUK - H.AŞAN}

değiştirmek imkânsızdır ve bu nedenle veri bozulduysa tüm düğümler içinde görülebilir bir hale gelir.

\subsubsection{Hesaplamalı Mantık}

BitShares (BTS) dijital bir ortamda olduğundan hesaplama mantığı, blok zincirdeki işlemlere bağlı olabilir. Dügümmler, işlemlerin otomatik tetiklenmesi için programlanmış algoritmaları veya kuralları kullanabilir (Iansiti ve Lakhani, 2008). BitShares (BTS) işlemler, sözleşmeler veya iş probleminin gerektirdiği her tür bilgi gibi her türlü bilgiyi ele alacak şekilde programlanabilir.

\subsection{Blok Zinciri Sınırları}

$\mathrm{Bu}$ bölümde blok zinciri teknolojisinin sahip olduğu bazı teknik sınırlılıklar anlatılmıştır. Yli-Huumo ve arkadaşları (2016) ve Swan (2016) blok zincir teknolojisinin bazı teknik zorluklar ile karşı karşıya olduğunu belirtmektedir; iş hacmi, gecikme, boyut ve bant genişliği, güvenlik, kaynak tüketimi, kullanılabilirlik, sürüm, zor çatallar ve çoklu zincirler ve mahremiyet. $\mathrm{Bu}$ teknik zorluklar teknolojinin engellenmesi adına bazı sınırlılıklar getiriyor ancak teknoloji bu sınırlılıkların üstesinden gelebilir. Yli-Huumo ve arkadaşlarının ortaya koyduğu sınırlılıklar blok zinciri teknolojisinin benimsenmesi adına endişe yarattığı düşünülürken, ağırlıklı olarak bu sınırlılıklar Bitcoin uygulamasına dayandırılmaktadır.

İş Hacmi: Mevcut blok zinciri teknolojisi bir saniyede yedi işlem yapabilirken, VISA saniyede 2000 işlem sağlayacak bir yapıya sahiptir.

Gecikme: Bir Bitcoin işlemi yeni bir blok oluşturma işlemi olarak yaklaşık olarak 10 dakika sürmektedir. Bu süre finans işlemleri için uzun bir zaman olduğu düşünülebilir. 
Boyut ve Bant Genişliği: Tüm Bitcoin blok zincirinin boyutu 100 GB' 1n üzerindedir (Şubat 2017). Her blok yaklaşık 1 MB boyuttadır. Her 10 dakikada bir blok eklenildiği düşünülürse, mevcut bant genişliği altyapısı işlem kapasitesinde sınırlama getirmektedir.

Güvenlik: Blok zincirinin $\% 51$ ' ne yapılacak bir saldırı yumuşaklık sorunları özgünlük veya kriptografi konularına tabi tutulabilir.

Kaynak Tüketimi: Yapısı gereği proof-of-work madenciliği ile veritabanındaki tutarlılığı sağlamak için her gün büyük miktarlarda enerji harciyor.

Kullanılabilirlik: Bitcoin uygulamaları için programlama arabirimi geliştirici dostu değildir ve kullanımı zordur.

Sürüm Oluşturma: Sabit Çatallar Ve Çoklu Zincirler: Farklı düğümler kaynak kodunun farklı sürümlerinde çalışabilir, bu da sorunlara neden olabilir. Topluluk geçmiş işlem tarihini belirli bir tarihe geri döndürmeye karar verirse, örneğin sahte bir işlemi bastırmaya çalışmak gibi zor bir çatal oluşur.

Gizlilik: Blok zincirinin sahipsiz yapısı sarsılabilir. Deneysel bulgular, işlemleri ve meta verileri analiz ederek Bitcoin Blockchain adresleriyle IP adreslerine ulaşabilir.

Güvenlik, yukarıda belirtilen kısıtlamaların ana araştırma konularından biridir. Boyut ve bant genişliği; verimlilik; versiyon, sabit çatallar ve çoklu zincirler gibi konularda yeterince araştırma yapılmamıştır (Yli-Huumo vd, 2016).

Teknik olarak bu sınırlılıkların yanında kültürel, örgütsel ve davranışsal kaygılarda bulunmaktadır. Khaqqi ve diğerleri (2018) bu kaygıları yönetim desteği, organizasyon politikaları ve blok zincirine kültürel adaptasyon 


\section{H.AVUNDUK - H.AŞAN}

sıralamıştır. Bu kaygılara ek olarak Mendling ve diğerleri (2017) devlet desteği ve çalışanların uzmanlık bilgisini eklemiştir.

\subsection{Blok Zinciri Türleri}

Blockchain erişim durumuna göre üç farklı türe ayrılır.

Genel (Açık) Blok Zincirleri: Genel blok zincirleri Bitcoin gibi geniş dağıtıma sahip ağlardır. Bu ağlara herkes herhangi seviyede katılabilir. Açık kaynak kodlarına sahiptir.

İzin Verilen Blok Zincirleri: Bu zincire katılacak kişilerin ağ içinde yapabilecekleri etkinliklerin izinlerini kontrol edebilen sistemlerdir. Kontrollü bir dizayna sahiptir. Yapıya göre açık kaynak kodlu olabilir. (Örnek: Ripple)

Özel Blok Zincirleri: Diğer blok zincirlerine göre daha küçük yapıdadır. Ağındaki kullanıcılara güvenen ve içerisinde gizli bilgiler bulunduran oluşumlar tarafından kullanılmaktadırlar.

\subsection{Blok Zinciri Çalışma Mekanizmasıı}

Blok zinciri çalışma mantığında verilere dayalı bir zincir yapısından bahsedebiliriz. İlk veri girişiyle başlayan zincir sonsuza kadar gidebilecek bir yapıya sahiptir. Verilerin eklenme süreci tek bir noktadan başlar ve bununla beraber zincire dahil olan tüm kullanıcılar eski verileri kendi sistemlerine yüklerler. Sonraki aşamada sisteme katılan kullanıcı bir kod üretir ve bu kod o an sistemdeki en uzun blok zincirine eklenir. Bu zincire ana zincir ismi verilir. Sistemdeki bütün bilgiler tüm zincirlerde saklanır.

\section{BLOK ZINCIR UYGULAMALARI}

İlk popüler uygulaması olan sanal para (bitcoin) ile tanınan Blockchain teknolojisinin birçok farklı alanda kullanılabileceği keşfedilmeye başlanmıştır. Teknolojinin zaman içinde geliştirilmesi ve tanınmasına 
paralel gelecekte uygulama alanlarının çok çeşitleneceğini söylenebilir. Aşağıda Blockchain teknolojisinin uygulamalarına ilişkin bir liste verilmiştir (Usta ve Doğantekin, 2017).

- Dijital Kimlik

- Müşteri Tanıma (Know Your Customer - KYC)

- Küresel Ödeme Sistemleri

- Girişimler İçin Sermaye İhtiyacı Karşılama

- Bağış Toplama ve Yönetimi

- Mal ve Kaza Sigortası Tazmin Süreci

- Nesnelerin İnterneti blockchaini

- Sendikasyon Kredisi

- Otomatikleştirilmiş Uyum Mekanizması

- Vekaleten Oy Kullanma

- Tedarik Zinciri Yönetimi

- Telif Kayit Sistemleri

- Tapu Kayit Sistemleri

- Kamu ve Sağlık Kayıtları ile İhaleler

- Askeri Emir Komuta Zincirleri

- Kopya Ürün Korumas1

- Noterlik uygulamas1 


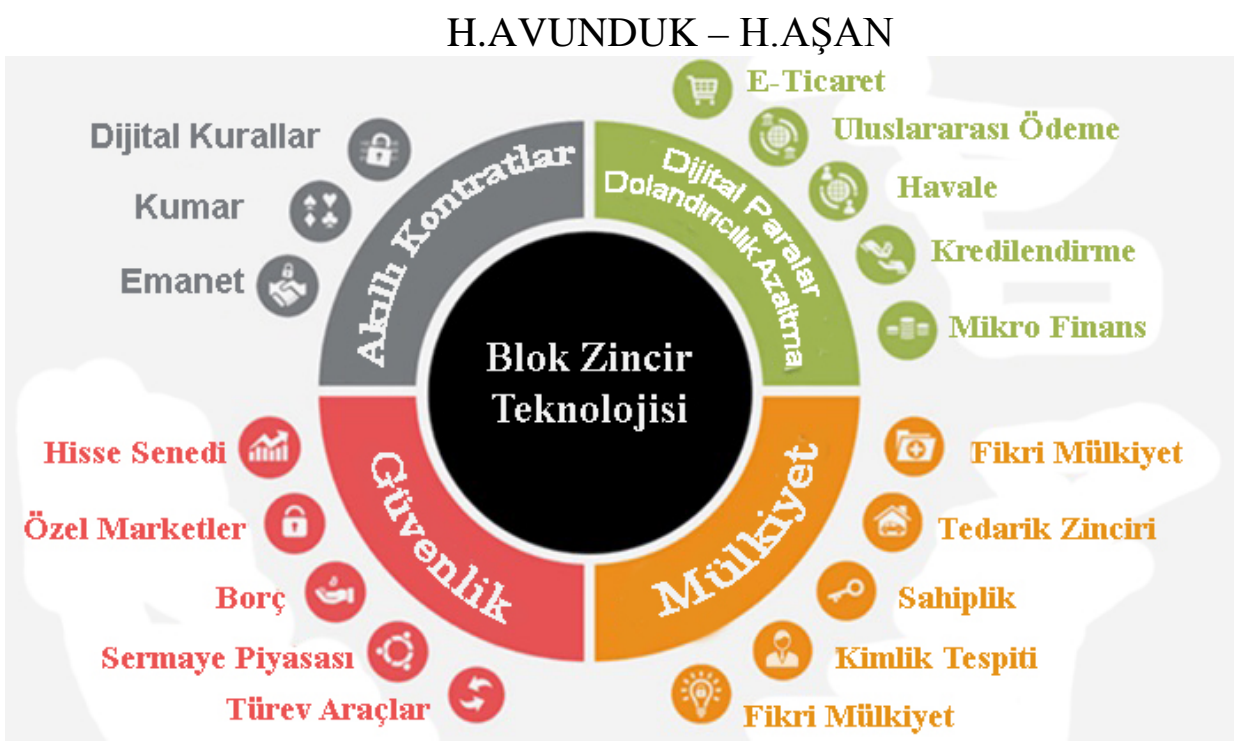

Şekil 3. Blok Zincir Uygulamaları Kaynak: Venkat, 2018.

\section{BLOK ZİNCİRİ TEKNOLOJISİ VE UYGULAMALARI KONUSU İLE}

\section{İLGILİ ARAŞTIRMA ALANLARI}

Blok zinciri üzerine yapılan akademik çalışmaların 2016 yılında bir patlama yaşadığını literatür kaynaklarından görebiliyoruz. Gelecek dönemde bu akademik çalışma sayısının daha da artacağını ileri sürmek çok zor değildir. Çalışmaların hala büyük bölümünün dijital para (bitcoin) üzerinde yoğunlaştığını görmek ile birlikte, giderek çalışmaların çeşitlenme eğiliminde olduğu izlenmektedir.

Oldukça yeni ve devrimsel olabileceği iddia edilen blok zinciri alanında yapılacak akademik çalışmalar, kullanıcıları, toplumu, aracıları, platformları, firmaları ve endüstrileri odak olarak alan şeklinde gruplandırılabilir. Aşağıda firmaları ve endüstrileri odak alan olasıl akademik çalışma konuları listelenmiştir (Risius ve Spohrer, 2017).

*Firmalar, blok zincir özelliklerini kendi iş süreçleri için nasıl kullanabilir? 
*Farklı şirket bölümleri veya endüstri kolları için hangi blok zincir özellikleri önemlidir?

* İlgili amaçlar için en uygun blok zinciri türü nedir?

*Blok Zinciri, şirket içinde veya müşteriler, tedarikçiler, hissedarlar ve devlet ile yürütülen işlemler sürecinde şirketlere nasıl bir katma değer sunabilir.

*Hangi pazarlar, endüstri kolları, iş modelleri veya kurumsal bölümler blok zincirden etkilenmeye daha yatkındır?

*Merkezi olmayan kontrol, endüstri çapındaki blok zincircileri sistemlerinde nasıl çalışır?

*Yeni örgüt formları bir blok zinciri üzerinde etkin bir şekilde yönetilebilir mi? Eğer öyleyse, nasıl ve neden?

*Kuruluşlar, veri gizliliği/güvenliği konusundaki farklı blok zinciri tabanlı uygulamalar altında nasıl davranmaktadır?

\section{SONUÇ}

Blok zincir teknolojisi, çıkış tarihi olarak daha geçmiş dönemlere dayansa da kripto paraların özellikle de Bitcoin isimli temeli Blok zincirine dayanan para ile birlikte popülerliğini son derece arttırmıştır. Bir anlamda Bitcoin isimli kripto paranın Blok Zincir teknolojisinin tanınırlık projesi olduğu söylenilebilir. Ancak Blok Zincir Teknolojisini sadece kripto para temelli ele almak son derece yanlış olacaktır. Geliştirilme amacı ve uygulama prensipleri gereği çeşitli özelliklere sahiptir. Bu özelliklerden en önemli ve göze çarpanları; desentralize yapı (merkezi bir yönetme sahip olmama), anonimlik, denetlenebilirlik ve sürdürülebilirliktir. Bu özellikleri sayesinde Blok Zincir teknolojisi geleneksel işletmecilik anlayışını radikal bir şekilde dönüştürme potansiyeline sahip olduğunu göstermektedir. 


\section{H.AVUNDUK - H.AŞAN}

Bitcoin ve sonrasında buna bağlı olarak ortaya çıkan kripto paralar Blok Zincirin tanınması ve kullanılması sürecinde etkin bir araç olarak görülmüş ve farkındalık yaratmış olsa da Blok Zinciri teknolojisinin gelecek projeksiyonlar anlamında yeni projelere kaynak olmaktadır.

$\mathrm{Bu}$ çalışmada öncelikle blok zincir teknolojisine ilişskin kapsamlı tanımlama ve değerlendirilme yapılmıştır. Özellikle bu teknolojinin Bitcoin ile karşılaştırılmaması gerektiği ve kendine has özelliklerinin geleceğe dönük faydalarına değinilmiştir. Bunun dışında teknolojinin günümüzde ve gelecekte ortaya çıkması ihtimal dâhilinde olan zorlukları ve riskleri konusuna değinilmiş, mevcut blok zincir uygulamaları çeşitli gruplar halinde sıralanmıştır. Teknolojisi anlamında sistematik olarak çalışabilir ve kullanılabilir olsa da tanınabilirlik ve uzman olmayan kişiler tarafından kullanılabilirlik anlamında henüz gelişim aşamasında olan blok zincir teknolojisinin söz konusu potansiyeli ve etkilerini kapsayan çeşitli akademik çalışma ihtiyacı ortaya konmuş ve olası akademik çalışma alanlarına ilişkin öneriler verilmiştir. Çalışma hem günümüz açısından hem de gelecek açısından bir tanımlama yapmak ve farkındalık yaratmak amacıyla ele alınmıştır.

\section{KAYNAKÇA}

Beck, R., Czepluch, J. S., Lollike, N., Malone, S. (2016), "Blockchainthe Gateway to Trust-Free Cryptographic Transactions". European Conference on Information Systems 2016, 153.

Crosby, M., Pattanayak, P., Verma, S., Kalyanaraman, V. (2016), “Blockchain technology: Beyond bitcoin. Applied Innovation”, 2, 6-10.

De Filippi, P. (2014), "Bitcoin: a regulatory nightmare to a libertarian dream". 
Hampton, N., (2016), "Understanding the blockchain hype: Why much of it is nothing more than snake oil and spin. Computerworld", http://www.computerworld.com.au/article /606253/ understandingblockchain-hype-why-much-it-nothing-more-than-snake-oil$\operatorname{spin} / .(10.12 .2017)$.

Iansiti, M., Lakhani, K., (2017), “The Truth About Blockchain”, Harvard Business Reveiw, Vol. 95, No. 1, pp. 118-127.

Khaqqi, K. N., Sikorski, J. J., Hadinoto, K., Kraft, M. (2018), "Incorporating seller/buyer reputation-based system in blockchain-enabled emission trading application”, Applied Energy, 209, 8-19.

Lemieux, V. L., Lemieux, V. L. (2016), “Trusting records: is Blockchain technology the answer?”, Records Management Journal, 26(2), 110-139.

Mendling, J., Weber, I., Van Der Aalst, W., Brocke, J. V., Cabanillas, C., Daniel, F., Gal, A. (2017), "Blockchains for business process managementchallenges and opportunities”.arXiv preprint arXiv:1704.03610.

Nakamoto, S., (2008), “Bitcoin: A Peer-to-Peer Electronic Cash System” , https://bitcoin.org/bitcoin.pdf, (25.10.2017).

Pilkington, M. (2016). "Blockchain technology: principles and applications”. Research handbook on digital transformations, 225.

Risius, M., Spohrer, K. (2017), “A Blockchain Research Framework”, Business \& Information Systems Engineering, 1-25.

Shcherbak, S. (2014), “How should Bitcoin be regulated”.Eur. J. Legal Stud., 7, 41.

Swan, M., (2015), ”Blockchain: Blueprint for a new economy”, O'Reilly Media, Inc.

Tian, F., (2016), “An agri-food supply chain traceability system for China based on RFID \& blockchain technology". Service Systems and Service Management (ICSSSM), 13th International Conference on. IEEE, 2016.

Tu, K. V., Meredith, M. W. (2015), "Rethinking virtual currency regulation in the Bitcoin age”, Wash. L. Rev., 90, 271. 


\section{H.AVUNDUK - H.AŞAN}

Usta, A., Doğantekin, S., (2017), “Blockchain 101”. Kapital Medya Hizmetleri A.Ş., ISBN: 978-605-4584-97-0, İstanbul

Vardi, N., (2016), "Bit by Bit: Assessing the Legal Nature of Virtual Currencies”. In Bitcoin and Mobile Payments (pp. 55-71). Palgrave Macmillan, London.

Venkat, A., (2018). "Blockchains and APIs", http://www.noahdatatech.com/blockchain-and-api/, (13.02.2018)

Xu, X., Pautasso, C., Zhu, L., Gramoli, V., Ponomarev, A., Tran, AB., Chen, S., (2016), "The blockchain as a software connector". 13th Working IEEE/IFIP conference on software architecture (WICSA), 2016, pp 182-191

Yli-Huumo, J., Ko, D., Choi, S., Park, S., Smolander, K., (2016), "Where Is Current Research on Blockchain Technology?” A Systematic Review. PloS one,11(10).

Zheng, Z., Xie, S., Dai, H. N., Wang, H. (2016), "Blockchain challenges and opportunities: A survey”. Work Pap.-2016. 